\title{
Large scale separation flow control experiments within the German Flow Control Network
}

\author{
J. Wild ${ }^{1}$ and G. Wichmann. ${ }^{2}$ \\ DLR German Aerospace Center, Braunschweig, 38108, Germany \\ F. Haucke ${ }^{3}$ and Inken Peltzer ${ }^{4}$ \\ Berlin Institute of Technology, Berlin, D - 105897, Germany \\ and \\ P. Scholz ${ }^{5}$ \\ Braunschweig Institute of Technology, Braunschweig, 38106, Germany
}

This is an overview on flow control experiments for flow separation control conducted in the DNW-NWB atmospheric low-speed wind tunnel performed within the German Flow Control Network. Emphasis is given on the experimental setup using the DLR F15 wall-to-wall two-dimensional high-lift model. Examples of successful flow control for enhancement of lift are given for leading edge boundary layer control and flap separation control, both by means of pulsed jet actuation.

\section{Nomenclature}

$\begin{array}{ll}c_{p} & =\text { pressure coefficient } \\ C_{L} & =\text { lift coefficient } \\ D C_{e} & =\text { excitation duty cycle } \\ c & =\text { retracted wing chord } \\ C_{F} & =\text { flap chord } \\ C_{W} & =\text { main wing chord } \\ c_{\mu} & =\text { excitation momentum coefficient } \\ f_{e} & =\text { excitation frequency } \\ M & =\text { Mach number } \\ p_{e} & =\text { excitation pressure } \\ R e & =\text { Reynolds number } \\ \alpha & =\text { angle of attack } \\ \delta_{F} & =\text { flap deflection angle } \\ I R & =\text { Infrared }\end{array}$

${ }^{1}$ Research Scientist, Institute of Aerodynamics and Flow Technology, Lilienthalplatz 7.

${ }^{2}$ Research Scientist, Institute of Aerodynamics and Flow Technology, Lilienthalplatz 7.

${ }^{3}$ Research Assistant, Department of Astronautics and Aeronautics, Marchstrasse 12-14.

${ }^{4}$ Research Assistant, Department of Astronautics and Aeronautics, Marchstrasse 12-14.

${ }^{5}$ Research Scientist, Institute of Fluid Mechanics, Bienroder Weg 3, AIAA Member 


\section{Introduction}

Future aircraft technologies see a need for slatless wing configurations due to upcoming technologies for achieving a reduced environmental impact of air traffic. Beyond the new technologies especially the enabling of natural or hybrid laminar wing technology is foreseen to be substantially able to decrease fuel burn. Additionally the present leading edge devices like slats have a high system complexity and omitting these systems provide a benefit in maintenance, costs and weight. Beyond this, especially slats are known to be the most significant source of airframe noise beside the landing gears in landing configuration of a transport aircraft ${ }^{1}$.

On the other hand slats are a powerful passive device for achieving high values of maximum lift. To be applicable, the lift loss resulting from slat removal must be recovered. If an increase of approach and landing speed is not meaningful, the lift can only be recovered by increase of wing area or an enhancing of lift coefficient by other means than leading edge devices. The solutions discussed nowadays are more complex trailing edge devices and active flow separation control.

Flow control research in Germany has a long tradition at Universities, both theoretical and experimental ${ }^{2}$. Especially the experimental investigations that have been performed in the past suffer limitations from the use of proprietary facilities, which lead to limited model sizes, restricted onflow velocities and thus Reynolds numbers which are too low for a real assessment of flow separation control concepts for large transport aircraft. On the other hand DLR has access to larger scale wind tunnels, resources for model manufacturing and a long tradition in high-lift research. By combining the activities of Universities and DLR an evaluation of flow control concepts at higher Reynolds numbers and more realistic high-lift configurations is enabled.

In 2004 the German Flow Control Network was established between DLR and three universities, namely the Institutes of Technology in Berlin, Braunschweig and Stuttgart. DLR is responsible for providing a large scale experimental test bed and access to the wind tunnel facility. The Berlin Institute of Technology investigates separation control actuation at the flap. The Braunschweig Institute of Technology focuses on separation control actuation at the leading edge. Additionally the Stuttgart Institute of Technology participates for a more detailed theoretical insight by providing direct numerical simulation of fluidic actuators; the results will not be discussed here.

Within 2004 and 2007 four wind tunnel entries were conducted with the DLR F15 two-dimensional highlift model in the atmospheric low speed wind tunnel DNW-NWB in Braunschweig. The first two entries addressed the stall behavior and the flow characteristics of the high-lift wing section. The last two entries were conducted applying active flow separation control at the leading edge and the flap of the model.

\section{Experimental Setup}

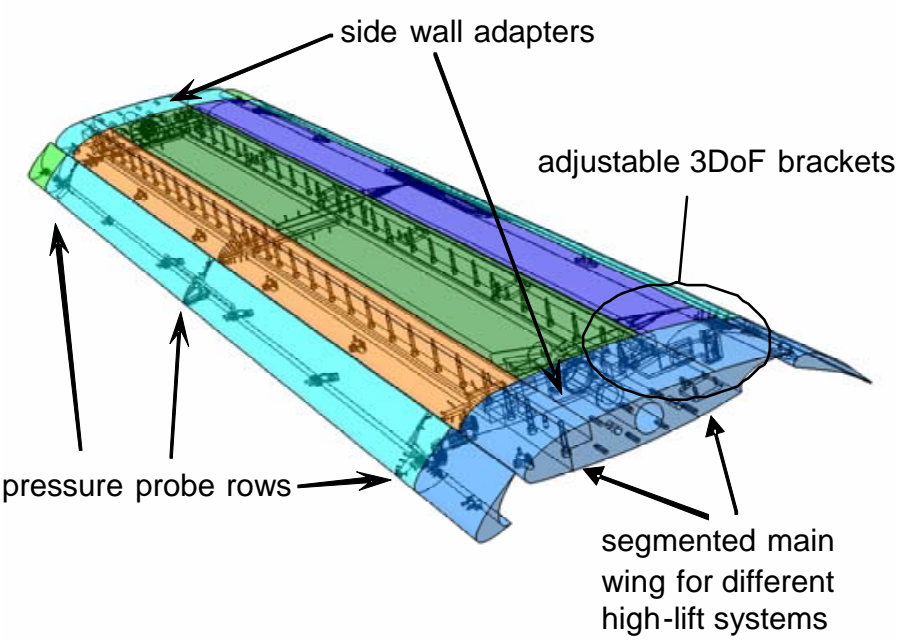

The DLR-F15 is a modular wind

Figure 1. General arrangement of the DLR F15 twodimensional high-lift model in 3-element configuration 
tunnel model for two-dimensional testing of different high-lift configurations. For the different configurations the complete leading and trailing edges can be exchanged. The model has a chord length of $600 \mathrm{~mm}$, the span can be varied from $2400 \mathrm{~mm}$ to $2800 \mathrm{~mm}$, depending on the test cross section of the used wind tunnel. Figure 1 depicts a sketch of the general arrangement of the model shown for the reference 3element configuration. The settings of high-lift devices are attached to the main wing with adjustable brackets for all three degrees of freedom. For the used 2-element configuration the flap deflection angle can be adjusted within the

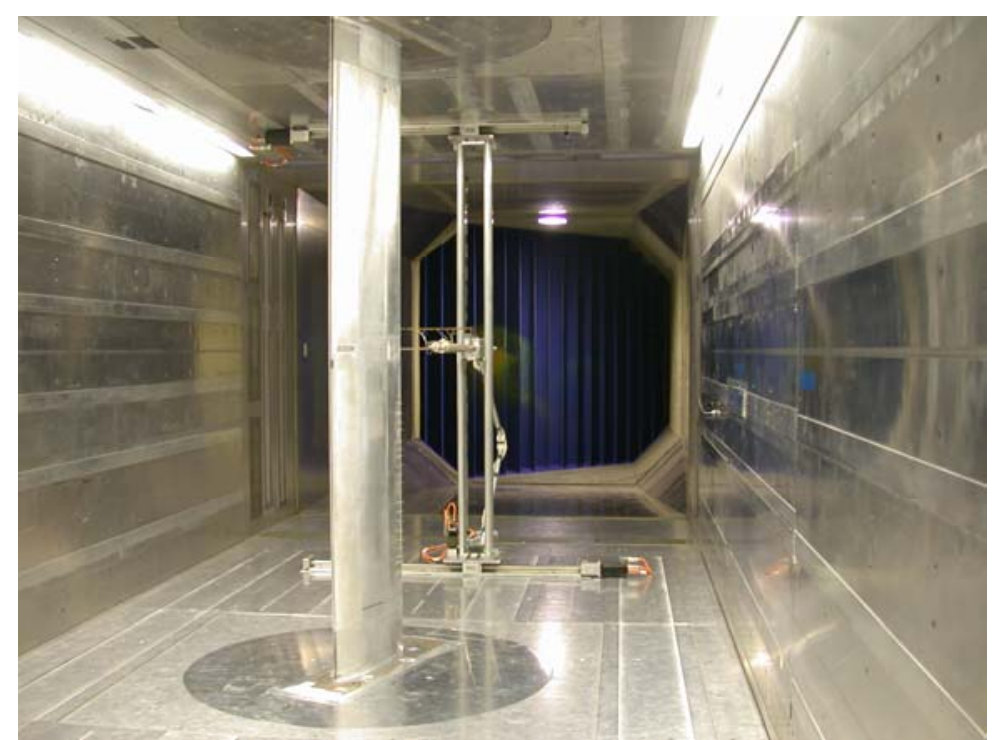

Figure 2. DLR F15 two-dimensional high-lift model mounted in closed test section of DNW-NWB atmospheric low speed wind tunnel range of $30^{\circ}-49^{\circ}$. The gap can be varied from completely closed to $4.7 \%$ clean wing chord. The possible overlap ranges from $-0.4 \%-4.3 \%$ clean wing chord.

The model is equipped with three rows of static pressure probes, one in the center section and two at the outer end in order to assess the two-dimensionality of the flow. The center section is used to derive the aerodynamic coefficients by surface integration and has therefore the double number of probes than the outer sections. Within the first wind tunnel entries a part of the wing was covered by plastics foil for infrared images for transition detection and verification of transition fixation.

The measurements were conducted in the DNW-NWB low speed facility. The model was mounted vertically in the closed $3.2 \mathrm{~m} \times 2.8 \mathrm{~m}$ test section on two synchronized turn tables. The tunnel was operated at Mach numbers between 0.05 and 0.2 , corresponding Reynolds number range of 0.5-2.7 Mio. Most of the measurements were conducted at $M=0.15$ and $R e=2.0 \times 10^{6}$.

Lift and moment coefficients were evaluated by surface pressure integration using the center section of pressure probes. Drag coefficients were measured using a wake rake. Figure 2 shows the model mounted in the DNW-NWB facility.

\section{Stall characteristics of reference configuration}

Knowledge about the separation behavior is a prerequisite for flow separation control. Within the first wind tunnel entries the stall characteristics at the wing and flap device were investigated. In order to avoid stall by laminar separation bubble burst special emphasis was put on a proper transition fixation. For this laminar-turbulent transition was monitored by infrared images for the unfixed case and different transition fixations. The optimum fixation method at the wing was found to be a $50 \mu \mathrm{m}$ tape of $2 \mathrm{~mm}$ width directly at the leading edge. Thicker tapes tended to overtrip and to generate an artificial separation behavior. Zig-zag-tapes have not been used, because the leading edge actuators intended to introduce longitudinal vortices, which may interfere in a very unfortunate way with the vortices created by the tape. 
Figure 3 shows a comparison of the IR images with and without transition fixation for the leading edge. Without fixation (left) a laminar separation bubble is observed, which is vanished after fixation (right). At the flap tapes of same thickness and width were applied at the flap leading edge and at 5\% flap chord. Two strips were necessary to cover both attached and separated flap flow over the complete range of incidences.

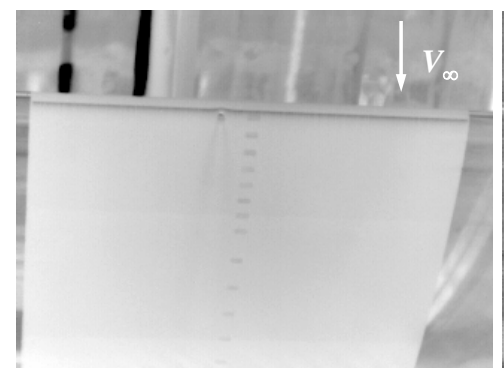

a)

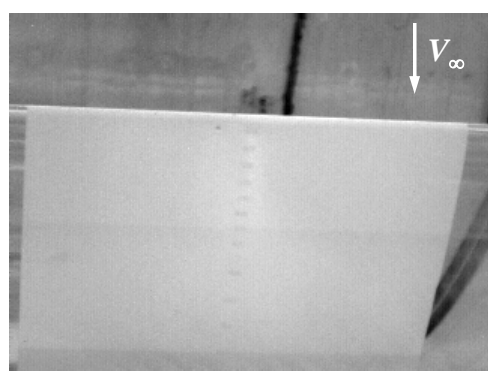

b)

Figure 3. Verification of transition fixation at the main wing leading edge with infrared images (upper side) at $\alpha=6^{\circ}, M=0.15, R e=2.0 \times 10^{6}$ : a) without fixation; b) with fixation with $50 \mu \mathrm{m}$ tapes of $2 \mathrm{~mm}$ width

Within the wind tunnel campaigns a series of different flap deflection settings were tested in order to achieve stall characteristics suitable for flow separation control. Especially for flap separation control a setting had to be found where the flap is separated over a larger range of angles of attack, since in the reference setting the flap is not detached at all.

\section{A. Leading edge stall}

A prerequisite for successful application of flow control at the leading edge is the existence of a leading edge stall. In order to not elaborate with the prevention of laminar separation bubbles the transition fixing mentioned already has been applied. Nevertheless, especially for 2-element high-lift systems, configurations with turbulent leading edge stall are possible due to the very low suction pressures and the corresponding high adverse pressure gradients downstream of the suction peak. This type of separation strongly relates to the setting of the flap. Therefore large ranges of setting variations have been performed in order to adjust the targeted separation behavior.

Figure 4 shows the pressure distributions of such a configuration just before and after stall onset. It is seen that this configuration deals with a detached flap flow, too. The leading edge stall is seen in the front part of the main wing, where the starting of the separation is visible up to $20 \%$ wing chord. It was verified by infrared images that there is no laminar flow in advance of the separation. Also, in the case of a laminar bubble burst the suction peak would not be present with this order of magnitude. Additionally, the trailing edge pressure varies only slightly, indicating that not a trailing edge separation is limiting lift in this case. This also may be supported by the reattaching flow on the flap.
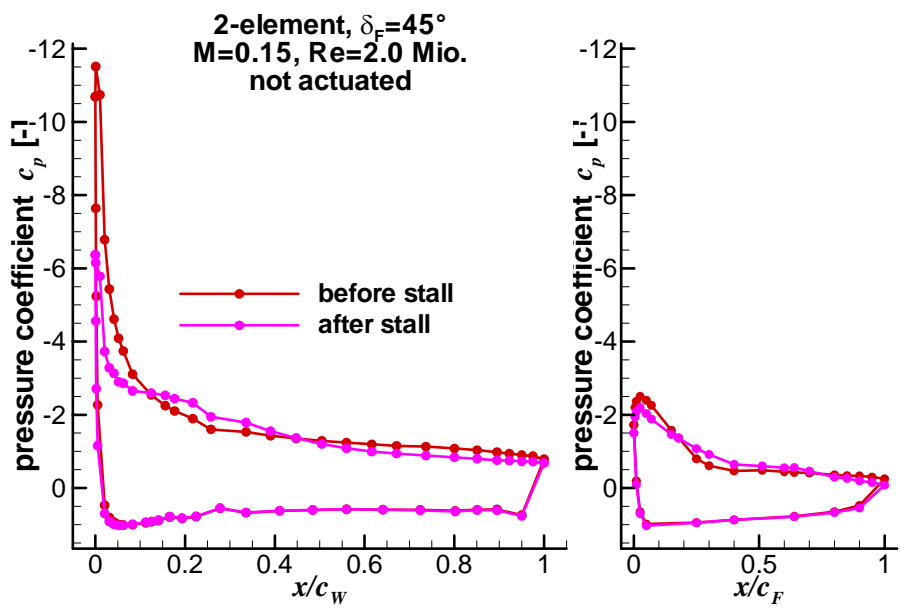

Figure 4. Turbulent leading edge stall verification by comparison of pressure distributions right before 


\section{B. Flap separation}

Turbulent flow separation on the trailing edge flap occurs if the flap is charged too much. In case of separation lift is reduced and drag increases drastically. While no flow separation occurs for the flap in reference configuration, massive separation sets in if the flap's angle of attack is increased by $10^{\circ}$ to $14^{\circ}$. Additionally, the occurrence and the extent of a flap separation are influenced by the flap gap.

In order to ensure a fully developed turbulent boundary layer flow at lower Reynolds numbers, small strips of tape are placed at suitable locations near the flap's leading edge. One setting for boundary layer tripping was found, that successfully forced laminar-to-turbulent transition and led to flow characteristics comparable to higher Reynolds number conditions.

Figure 5 shows a comparison of lift curves for three different flap deflection angles and the

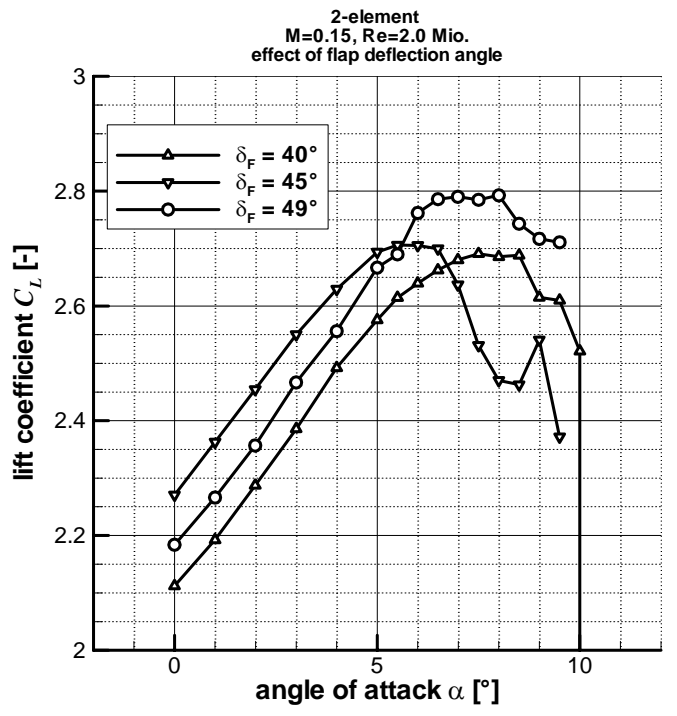

a)
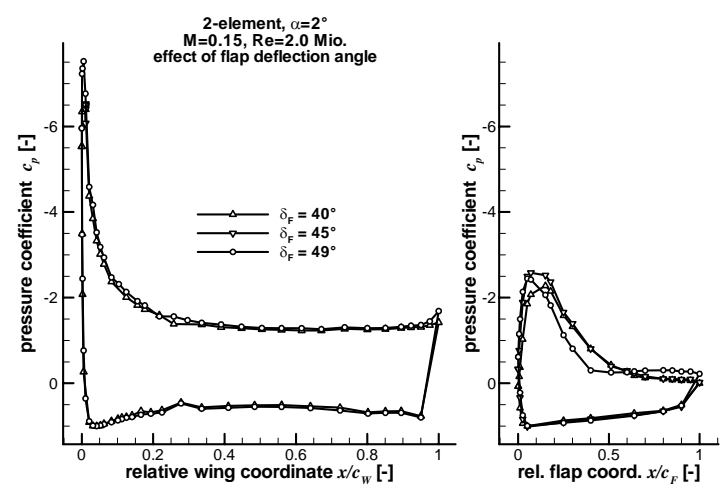

b)

Figure 5. Influence of flap deflection on flap separation for three different flap deflection angles: a) lift curves; b) pressure distributions at $\alpha=2^{\circ}$

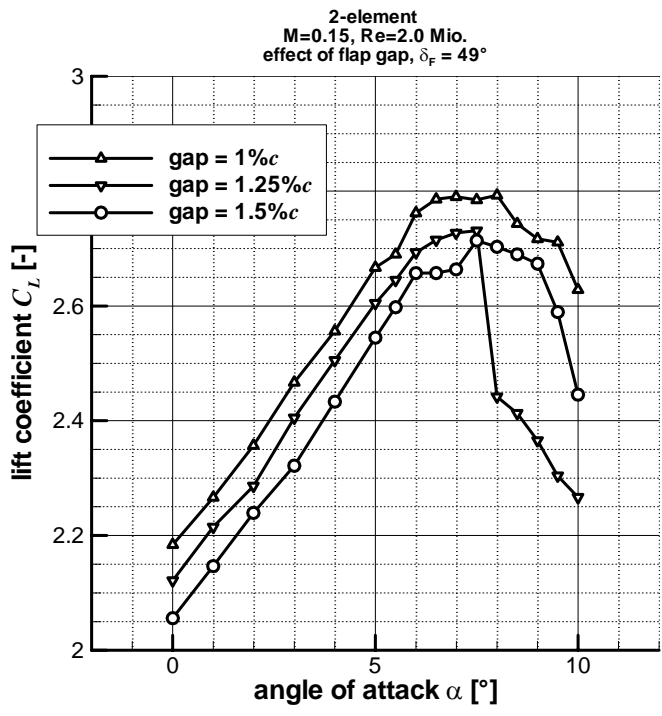

a)

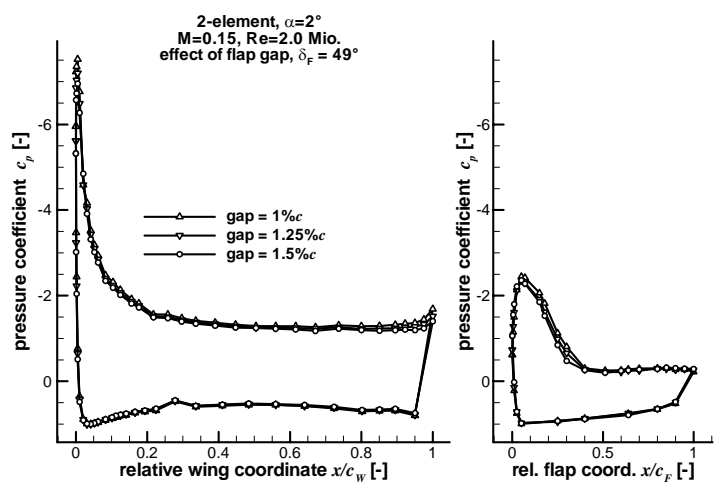

b)

Figure 6. Influence of flap gap on flap separation for three different gap settings at $49^{\circ}$ flap deflection angle: a) lift curves; b) pressure distributions at $\alpha=2^{\circ}$ 
corresponding pressure distributions at an angle of attack of $\alpha=2^{\circ}$. For the two smaller flap deflection angles, turbulent flow separation on the flap starts at about $65 \% c_{F}$ and is shifted upstream to a location at approximately $35 \% \quad c_{F}$ for higher deflection angles of the flap. The larger the separation area the higher is the potential for gaining lift, if the flow is successfully reattached by flow control.

Figure 6 shows lift curves and pressure distributions at an angle of attack of $\alpha=2^{\circ}$ for a flap gap variation at the largest flap deflection angle. An increased gap results in higher losses in lift coefficient, while the location of flap separation is varied within $10 \% c_{F}$.

\section{Side wall separation}

A major critical item for experimental investigation of two-dimensional wall-to-wall models is the presence of the boundary layers at the wind-tunnel walls. Depending on the aspect ratio and the lift generated by the wing a separation can occur in the junction of the model with the tunnel walls. This separation is able to disturb the complete model leading to erroneous measurements especially in the nonlinear regime. The prevention of side-wall separations has been investigated mainly by means of suction or blowing at the wind tunnel walls (e.g. Ref. 3). A common result of these investigations is that the suction or blowing rate cannot be specified in advance and is able to produce artificial results. The shortcoming of these methods is related to the fact that the correct blowing or suction is depending not only on the evolution of the wall boundary layer but also on the boundary layer of the tested airfoil. By this the needed flow rate is related to the circulation of the airfoil and therefore depending on the incident.

In our wind tunnel experiments we tried also another method for prevention of the side-wall stall. For the DLR-F15 model different types of leading edge devices exist, also for the sidewall-adapters. In special tests the side-wall-adapters of the clean nose were exchanged with those of a droop nose configuration. Such a device reduces the loading of the boundary layer proportionally to the circulation around the airfoil.

Figure 7 shows a comparison of the lift coefficients over the angle of attack for the two different adapters together with the pressure distributions for both configurations, each taken for the angle of attack where maximum lift occurs. It is observed that using the droop nose adapters

American Institute of Aeronautics and Astronautics 092407 
the kink in the linear slope is no longer existent. Detailed analysis of mini-tuft videos showed that for the observed left wing the side wall separation did not occur before stall of the main wing. The pressure distributions showed a slightly earlier stall on the right hand wing side edge. The pressure distributions of the center wing section for both adapter configurations show an identical pressure distribution just before stall. Only a slight variation in the size of the flap separation is observed. This led to the assumption that the error made by allowing the side wall separation is mainly to be addressed to the incidence, not to the pressure distribution. An explanation is proposed to be due to induced flow by an increasing span wise nonuniformity of the flow. Nevertheless, the stall mechanism itself seems to be unaffected.

Unfortunately this device could not be used for the flow control experiments, since the contours of droop nose and clean wing do not match in the area where the pressurized air duct is located.

\section{Flow control actuation}

All flow control actuations are made by pulsed jet blowing. Pressurized air, which is gained from an external screw compressor at a maximum delivery rate of $10 \mathrm{~m}^{3} / \mathrm{min}$ at $12 \mathrm{bar}$, is supplied by tubes into the model air ducts up to fast switching solenoid valves. These valves can be operated at a maximum frequency of $300 \mathrm{~Hz}$. The valves are located as close as possible to the actuator chambers to retain the high frequencies and approximately square signals for the proper pulsed jet actuation.

\section{A. Actuations on main wing}

The principle for controlling leading edge flow separation was developed by TU Braunschweig ${ }^{4}$. It utilizes pulsed vortex generator jets, e.g. skewed slots or holes as described by Scholz et al. ${ }^{5}$.

For the main wing flow control actuation a second clean wing leading edge element was manufactured. Figure 8 shows a sketch of the model part. The

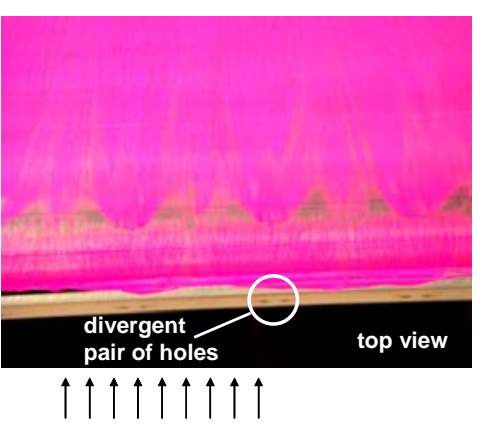

a)

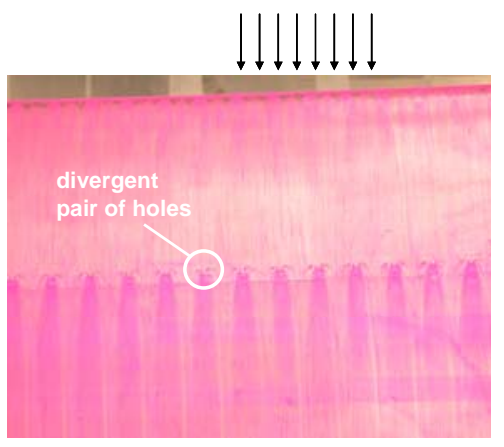

b)
Figure 9. Oil flow pictures with leading edge actuated by convergent-divergent holes: a) lower leading edge; b) $25 \%$ retracted wing chord

American Institute of Aeronautics and Astronautics 092407 
actuator chambers directly were milled into the material. The chambers are afterwards covered by sheets defining the shape of the flow actuators, either slots or holes. By this the type of actuation was easily exchanged during the wind tunnel campaigns and allowed for the investigation of different principles.

Actuations are provided at the lower and/or upper side of the leading edge as well as at the upper side at $25 \%$ chord. At the leading edge convergent-divergent pairs of holes and slots were tested, where the holes were examined to be more effective. Figure 9 shows an oil flow picture after an actuation at the leading edge lower side (left) and at $25 \%$ chord (right). The vortices generated by the pulsed jets form a typical pattern of surface stream lines on the upper side. This verifies that the generated vortices sustain

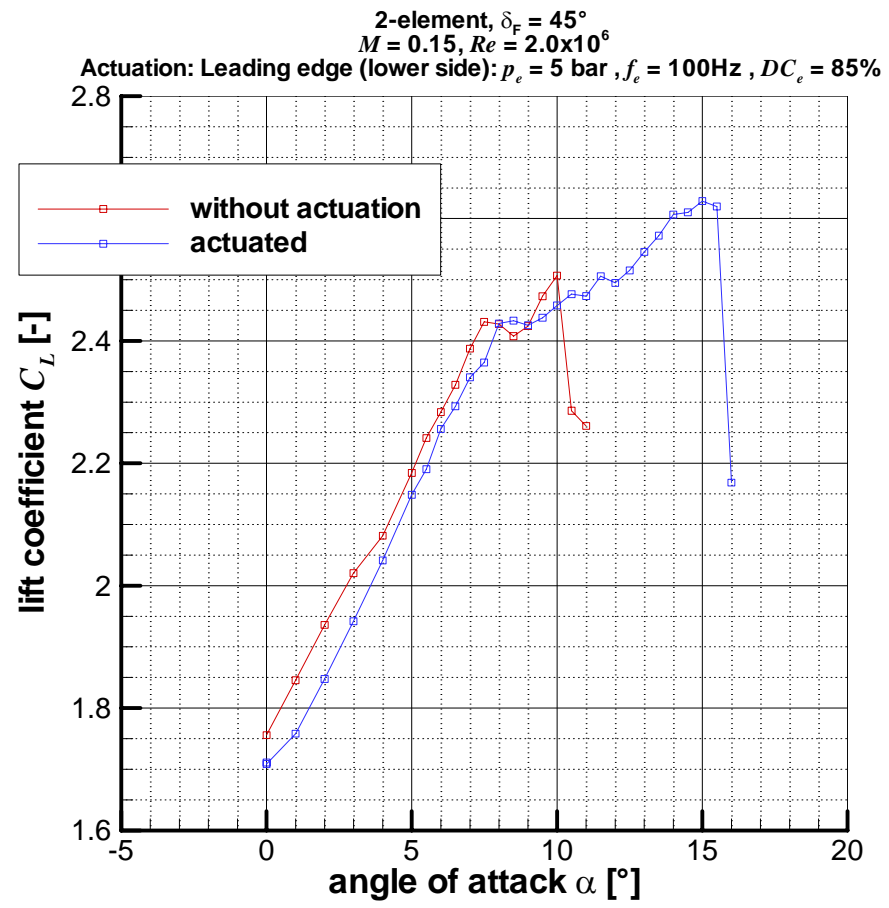

Figure 10. Comparison of lift coefficient over angle of attack with and without leading edge separation control the strong acceleration and deceleration of the flow around the leading edge.

Figure 10 exemplarily shows the lift coefficient over the angle of attack without actuation and with an actuation at $p_{e}=5$ bar and $f_{e}=100 \mathrm{~Hz}$ and a duty cycle of $D C_{e}=85 \%$. The flap deflection in this case was set to a deflection angle $45^{\circ}$. The major effect is seen to be a delay of separation towards higher angles of attack by approximately $5^{\circ}$. In the linear range the actuation slightly reduces the lift coefficient. It has to be mentioned, that there was neither an actuation at the side wall adapters nor the droop nose adapters were used. By this the side wall separation occurs before wing stall, which is, as already mentioned, responsible for the change of the slope of the lift curve.

Further details on the leading edge actuation are given by Scholz ${ }^{10}$.

\section{B. Active flow control at flap}

Active separation control using pulsed jets from the flap shoulder was introduced by Berlin Institute of Technology ${ }^{6-9}$.

Compressed air, a fast switching solenoid valve and a specially designed actuator chamber are the three main components of one actuator segment.

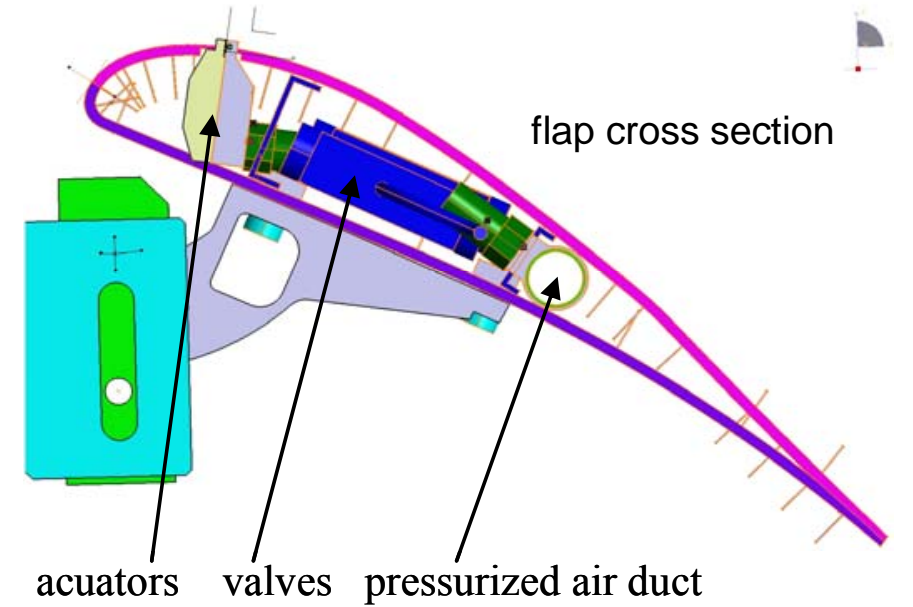

Figure 11. Cross section through the flow control flap depicting the arrangement of the actuation 8

American Institute of Aeronautics and Astronautics 092407 
Figure 11 shows the actuator system within the flap, which was manufactured with carbon fiber reinforced plastics (CFRP). Thus, optimal stiffness is achieved while sufficient space inside the flap for mounting the flow control excitation system is kept free. For the presented high lift configuration 28 of these actuation segments were integrated into the flap covering the complete span wise extension, and two positions of excitation, located at $10 \%$ and $20 \%$ of the flap's chord length, have been investigated.

Figure 12 shows exemplary lift curves for a flap deflection angle of $49^{\circ}$ without and with active flow control on the flap's shoulder at $20 \%$ $C_{F}$. For the unexcited case a large separation area occurred starting at about $35 \% c_{F}$, see fig. $6 \mathrm{~b}$, and is present for the whole range of angles

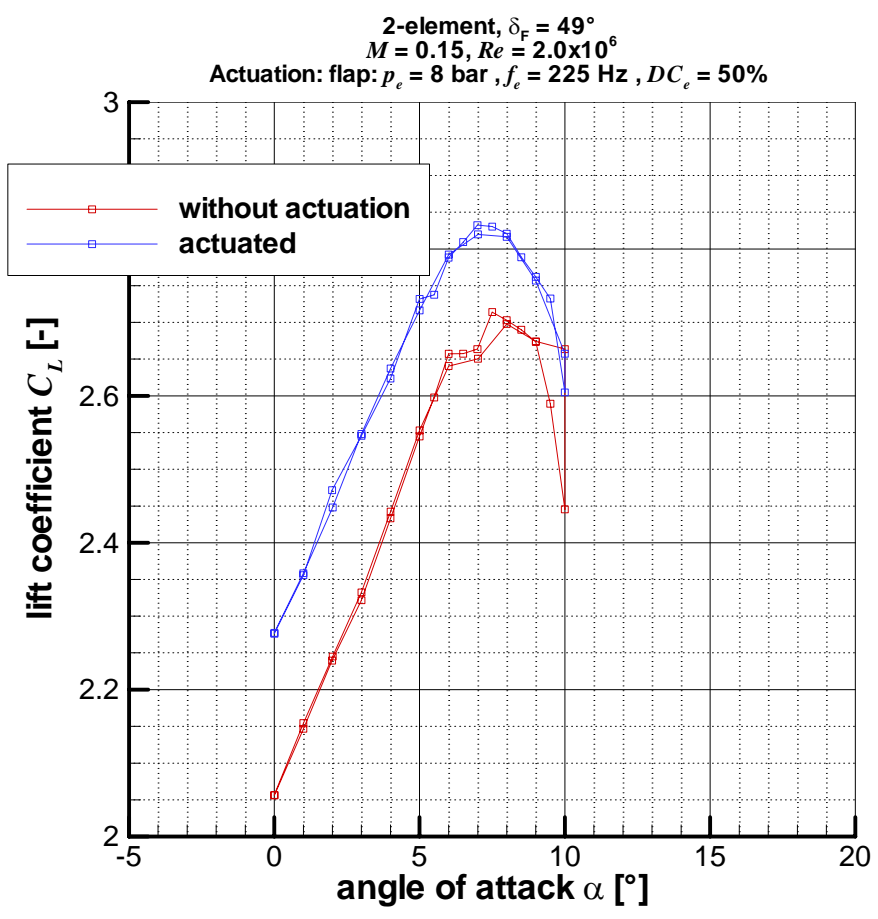

Figure 12. Comparison of lift coefficient over angle of attack with and without flap separation control

of attack. Exciting the flow with a frequency of $f_{e}=225 \mathrm{~Hz}$, a duty cycle of $D C_{e}=50 \%$ and a duct pressure of $p_{e}=8$ bar leads to a reattachment of the flow on the flap, which results in an enhancement of the lift coefficient of up to $10 \%$ in the linear region of the presented lift polar. The corresponding momentum coefficient is in average about $c_{\mu} \approx 0.25 \%$.

\section{Conclusion}

A series of wind tunnel experiments with the two-dimensional high-lift model DLR-F15 have been performed for investigation of active flow separation control on the wing and on the flap of a 2-element configuration. The separation behavior has been analyzed in detail and the configuration has been adjusted in terms of flap settings in order to select the most appropriate configurations. Flow separation control by pulsed jet actuation has been successfully applied for delaying wing leading edge stall and preventing flap separation.

Nevertheless, all aerodynamic performance gains have been obtained on "artificial" flap settings, leading to the desired type of separation. It should not be concealed that still a properly adjusted flap setting tends to provide higher aerodynamic performance than those obtained with flow control on non-optimum flap settings. This additionally raises the request for devices specifically designed for flow control instead of trying retro-fit solutions on systems optimized for attached flow. 


\section{Acknowledgments}

This work was funded by the German government within the frame of the $3^{\text {rd }}$ Aerospace Research Program (LuFo III). The authors would like to thank M. Gülzow, K. de Groot and Th. Weddig for the support with the wind tunnel model and the infrared images.

\section{References}

1 Dobrzynski, W., Gehlhar, B. and Buchholz, H., "Model and full scale high lift wing wind tunnel experiments dedicated to airframe noise reduction. Aerospace Science \& Technology, vol. 5, no. 1 (2001),pp. 27-33

2 Schlichting, H., Grenzschicht-Theorie, $5^{\text {th }}$ edition, Verlag G. Braun, Karlsruhe (1965), pp. 636-640.

3 Englar, R.J., "Development of pneumatic test techniques for subsonic high-lift and in-ground-effect wind tunnel investigations", Wall Interference, Support Interference and Flow Field Measurements, AGARD CP 535 (1993).

Scholz, P., Ortmanns, J., Kähler, C.J. and Radespiel, R., "Influencing the Mixing Process in a Turbulent Boundary Layer by Pulsed Jet Actuators", New Results in Numerical and Experimental Fluid Mechanics V: Contributions to the 14th STAB/DGLR Symposium, Bremen 2004, edited by Rath, H.J., Holze, C., Heinemann, H.J., Henke, R., Hönlinger, H., , Vol. 92, pp.265-272 (2006).

Scholz, P., Casper, M., Ortmanns, J., Kähler, C.J. and Radespiel, R., „Leading Edge Separation Control by Means of Pulsed Vortex Generator Jets", AIAA Journal, Vol. 46, No. 4, pp 837-846 (2008).

6 Becker, R. and King, R and Petz, R. and Nitsche, W., "Adaptive Closed-Loop Separation Control on a High-Lift Configuration sing Extremum Seeking”, AIAA Journal, Vol. 45, No. 6, pp. 1382-1392 (2007).

7 Petz, R. and Nitsche, W., “Active Separation Control on the Flap of a Two-Dimensional High-Lift Configuration”, Journal of Aircraft, Vol. 44, No. 3, pp. 865-874 (2007).

8 Petz, R. and Nitsche, W., "Active Control of Flow Separation on Swept Constant Chord Half Model in a High-Lift Configuration", 3rd AIAA Flow Control Conference, AIAA paper 2006-3505 (2006).

9 Haucke, F., Peltzer, I. and Nitsche, W., "Active Separation Control on a Slatless 2D High-Lift Wing Section", 26 ${ }^{\text {th }}$ International Congress of the Aeronautical Sciences, Anchorage USA (2008).

10 Scholz, P., "Active Control of Leading Edge Separation Within the German Flow Control Network", $47^{\text {th }}$ AIAA Aerospace Sciences Meeting, AIAA-2009-0529 (2009). 